\title{
PAULO FREIRE E A UNESCO: ANÁLISE DE RECOMENDAÇÕES DE POLÍTICAS DE EDUCAÇÃO DE ADULTOS
}

\author{
PAULO FREIRE AND UNESCO: ANALYSIS OF \\ RECOMMENDATIONS ON ADULT EDUCATION POLICIES
}

\section{PAULO FREIRE Y UNESCO: ANÁLISIS DE RECOMENDACIONES DE POLÍTICAS DE EDUCACIÓN DE ADULTOS}

Paula Guimarães ${ }^{1}$

https://orcid.org/0000-0002-2197-1004

Hernani Sumbo ${ }^{2}$

https://orcid.org/0000-0003-0747-931X

${ }^{1}$ Instituto de Educação, Universidade de Lisboa, Lisboa - Portugal. E-mail: pguimaraes@ie.ulisboa.pt

${ }^{2}$ Instituto de Educação, Universidade de Lisboa, Lisboa - Portugal. E-mail: hernanisumbo@campus.ul.pt

\section{Resumo}

Paulo Freire é um autor importante para as políticas de educação de adultos e seu pensamento foi valorizado pela UNESCO em diferentes circunstâncias e documentos. Entre esses documentos, para o caso da educação de adultos, contam-se a Recomendação para o Desenvolvimento da Educação de Adultos (1976) e a Recomendação sobre a Aprendizagem e Educação de Adultos (2015). A análise dessas recomendações é levada a cabo neste artigo a partir da proposta de Lima e Guimarães (2018), a qual integra a lógica democrática e emancipatória que se beneficia do contributo de Freire. A questão que orienta a análise neste artigo é a seguinte: que dimensões políticas e educativas enunciadas pelas Recomendações de Aprendizagem e Educação da UNESCO (1976 e 2015) remetem ao contributo de Freire? Por meio da análise documental e da análise de conteúdo resgatam-se as dimensões políticas e educativas enunciadas nas recomendações, com particular destaque para os conceitos como educação como prática de liberdade que, de cariz emancipatório e democrático, apelam à educação problematizadora, conscientização e dialogicidade.

Palavras-chave: Paulo Freire. Educação como prática de liberdade. Políticas de educação de adultos. Lógicas políticas. UNESCO. 


\begin{abstract}
Paulo Freire is a relevant author for adult education policies and this author was stressed by UNESCO in several circumstances and documents. Among these documents, in what refers to adult education, are the Recommendation for the Development of Adult Education (1976) and the Recommendation of Adult Learning and Education (2015). The analysis of the Recommendations is made in this article following the Framework of Lima \& Guimarães (2018). This Framework includes the democratic and emancipatory logic that is based on Freire thinking. The question to be answered in this article is the following: what policy and educational dimensions that are to be found in the Recommendations of adult learning and education of UNESCO (1976 and 2015) refer to Freire's thinking? Following document analysis, policy and educational dimensions of the referred Recommendations are approached, in specific what relates to concepts such as education as freedom practice, according to an emancipatory and democratic nature, that links to problematising education, conscientization and dialogicity.
\end{abstract}

Keywords: Paulo Freire. Education as freedom practice. Policies of adult education. Policy logics. UNESCO.

\title{
Resumen
}

Paulo Freire es un autor importante para las políticas de educación de adultos y el pensamiento de este autor ha sido valorado por la UNESCO en diferentes circunstancias y documentos. Entre esos documentos, en el caso de la educación de adultos, se encuentran la Recomendación para el desarrollo de la educación de adultos (1976) y la Recomendación sobre el aprendizaje y la educación de adultos (2015). El análisis de esas recomendaciones se realiza en este artículo a partir de la propuesta de Lima y Guimarães (2018). Esta propuesta integra la lógica democrática y emancipadora que se beneficia del aporte de Freire. La pregunta que guía el análisis en este artículo es la siguiente: ¿Qué dimensiones políticas y educativas enunciadas por las Recomendaciones de Aprendizaje y Educación de la UNESCO (1976 y 2015) se refieren a la contribución de Freire? A través del análisis documental y de contenido, se abordan las dimensiones políticas y educativas recogidas en las recomendaciones, con especial énfasis en conceptos como la educación como práctica de libertad que, de carácter emancipatorio y democrático, exigen problematizar la educación, la conciencia y la dialogicidad.

Palabras clave: Paulo Freire. Educación como práctica de libertad. Políticas de educacíon de adultos. Lógicas políticas. UNESCO.

\section{Notas introdutórias}

No campo da educação de adultos, Freire surge como um autor de referência devido, entre outros, ao seu entendimento de educação como prática de liberdade. No quadro da ação das organizações internacionais, diversas propostas de cariz político, democrático e emancipatório beneficiaram-se do pensamento de Freire. Entre as 
organizações internacionais governamentais, a UNESCO apresenta-se como uma das que mais recorreram ao contributo do referido autor, como se pode verificar em diferentes documentos e eventos. Em diversos momentos da sua vida, Freire colaborou com essa organização, como no período em que foi consultor na redação do Relatório Faure (FAURE et al., 1972), no início da década de 1970. Mais tarde, como resultado do trabalho no contexto da educação (de adultos e popular, assim como da alfabetização crítica), Freire foi várias vezes homenageado, tendo sido distinguido, em 1975, com o prêmio de alfabetização e, em 1986, com o Prêmio UNESCO da Educação para a Paz ${ }^{1}$ (FREIRE, 2006). No quadro das conferências internacionais de educação de adultos, a CONFINTEA V, entre outras, referiu-se a Freire como uma figura incontornável da educação (UNESCO, 1999); adicionalmente, a Década das Nações Unidas para a Alfabetização para Todos - 2003-2012 (Resolução $n^{\circ}$. 56/116) foi declarada em sua homenagem. Paulo Freire foi também uma figura importante para a Cátedra da UNESCO Educação, Cidadania e Diversidade Cultural e para o programa Memória do Mundo $^{2}$, que conta com um acervo de documentos diversos sobre ele.

Na educação de adultos, a UNESCO surge como uma importante organização em termos de produção acadêmica e normativa (NEMETH, 2016). Ao criar condições para o estabelecimento de diálogo entre os estados-membros e para a aprovação de documentos políticos diversos, essa entidade tem estabelecido condições para a existência de consensos políticos e para a transferência política para países que adotam esses textos nos programas públicos, abrindo igualmente espaço para a recontextualização das orientações que tais documentos integram. Entre esses textos, as Recomendações para o Desenvolvimento da Educação de Adultos (1976) e sobre a Aprendizagem e Educação de Adultos (2015) contribuíram para a definição do campo da educação de adultos e para a criação de entendimentos políticos partilhados nesse domínio, favorecendo o que Milana (2014) designa de o surgimento de uma política global (global polity) ${ }^{3}$.

\footnotetext{
${ }^{1}$ Disponível em: https://www.paulofreire.org/paulo-freire-patrono-da-educacao-brasileira, Acesso em: 22 jun. 2021.

2 Disponível em: https://en.unesco.org/sites/default/files/list-unesco-chairs.pdf e https://en.unesco.org/programme/mow. Acesso em: 22 jun. 2021.

${ }^{3}$ Esta circunstância é particularmente clara nas variações que podem ser identificadas na definição de educação de adultos. No caso das recomendações em análise, essas integraram diferentes definições de educação de adultos/educação e aprendizagem de adultos, que foram usadas posteriormente em muitos documentos políticos da UNESCO publicados posteriormente. Também, nas declarações das Conferências Internacionais de Educação de Adultos (CONFINTEA) IV, V e VI, e, mais recentemente,
} 
Guimarães, P. e Sumbo, H.

Neste artigo, pretendemos analisar dois documentos normativos (NEMETH, 2016) da UNESCO que influenciaram muitos outros produzidos por essa entidade. Esta análise é efetuada a partir da proposta de Lima e Guimarães (2018) que integra diferentes lógicas políticas, entre elas a lógica democrática e emancipatória, articulável com o conceito de educação como prática de liberdade, desdobrado noutros como educação problematizadora, conscientização e dialogicidade. Esta discussão visa a compreender a influência do contributo de Freire com as dimensões políticas e educativas enunciadas nas recomendações (UNESCO, 1977, 2017) já referidas.

\section{Paulo Freire: educação de adultos como prática de liberdade}

É reconhecido por diversos autores (MAYO, 1995; GADOTTI, 1997; GADOTTI; TORRES, 2009; LIMA, 2019) que Freire contribuiu de modo marcante para as políticas, as práticas e a investigação em educação de adultos em todo o mundo. Tal como destacam Finger e Asún, no que a reflexão sobre as políticas diz respeito, Freire "deixou um importante legado, que tem sido objeto de inúmeras dissertações, livros e discussões críticas" (FINGER; ASÚN, 2003, p. 80). Essa reflexão baseou-se em diferentes conceitos, concretamente no de educação como prática de liberdade e problematizadora, conscientização e dialogicidade, centrais em diversas políticas públicas, ideias essas referenciadas até por organizações internacionais governamentais, como a UNESCO.

Na reflexão política, o contributo de Freire para a educação de adultos destaca-se pela prioridade concedida à liberdade dos sujeitos. Ideia central no pensamento do autor, a liberdade é considerada uma possibilidade que permite aos sujeitos, no quadro da ação coletiva, serem os atores principais na intervenção social, tendo em vista a transformação do mundo (GADOTTI, 1997; FREIRE, 2018). Nesse sentido, a liberdade se assenta na expressão autêntica do pensamento e da palavra. Essas duas unidades são de resto complementares e fundem-se na dialética entre a dimensão reflexiva e a intervenção do mundo dos sujeitos.

nos Relatórios Globais de Educação e Aprendizagem de Adultos (Global Reports on Adult Learning and Education [GRALE]), esta variação pode ser identificada (ELFERT, 2015). 
A prática da liberdade como eixo central do pensamento freiriano encontra-se fundamentada na educação problematizadora, na conscientização e na dialogicidade. $\mathrm{O}$ conceito de educação problematizadora concede centralidade à análise crítica da realidade dos sujeitos, os quais, na qualidade de educandos, atuam como atores que refletem e transformam a realidade em que vivem. Esse conceito enfatiza a não acomodação e a não naturalização do status quo social, político, econômico e cultural. No quadro da educação problematizadora, os sujeitos praticam a liberdade quando ganham a capacidade de compreender de forma crítica o mundo, numa relação constante entre as pessoas e a vida, num processo dinâmico e em transformação (GADOTTI, 1997; FINGER; ASÚN, 2003; FREIRE, 2018). A análise crítica da realidade incide igualmente sobre as ações, comportamentos e rotinas e sobre as condições existenciais da vida dos sujeitos, a partir de fundamentos socio-históricos inscritos na relação espaço-tempo. Nesse âmbito, a reflexão e a ação fundem-se como elementos de uma mesma unidade, a práxis, pois as duas dimensões fazem parte do mundo a ser transformado pelos e com os sujeitos no contexto da intervenção coletiva. Assim, Freire defende que ninguém transforma ninguém e ninguém se transforma sozinho; os homens libertam-se, transformam-se e desenvolvem-se em comunhão (FREIRE, 2018).

A educação problematizadora opõe-se à educação bancária. O antagonismo entre esses dois conceitos se assenta nas ideias de libertação, no caso da educação problematizadora e de opressão, no caso de educação bancária (MAYO, 1995; GADOTTI, 1997). No primeiro, a educação visa à superação, à (re)criação e à libertação e incide no ato humano da crítica, traduzido no "pensar autêntico, e não no sentido da doação, da entrega do saber. Sua ação deve estar infundida na profunda crença nos homens" (FREIRE, 2018, p. 67). No segundo, a educação domina e oprime os sujeitos e passa pelo "ato de depositar, de transferir, de transmitir valores e conhecimentos" (FREIRE, 2018, p. 65).

A educação, fundamentada na problematização, desperta nos sujeitos a conscientização como processo que objetiva refletir, entender e agir de forma crítica e ativa sobre os fenômenos que ocorrem no mundo e nas condições de vida das pessoas. Segundo Freire, "à medida que um método ativo ajude o homem a se conscientizar em torno de sua problemática, em torno de sua condição de pessoa, por isso de sujeito" (FREIRE, 1967, p. 119), a conscientização liberta, pois permite que os educandos 
tenham plena consciência de si como agentes ativos de transformação social. Os sujeitos deixam de ser espectadores para serem atores principais na (re)construção do meio político, social e cultural. A compreensão da realidade permite que os educandos conheçam e se reconheçam nas ações realizadas em conjunto com outros atores políticos, sociais e educativos.

A conscientização também implica a reflexão e a prática crítica (FREIRE, 1967; FINGER; ASÚN, 2003). Esse ato remete para a intervenção dos sujeitos na busca de alternativas à realidade social que vivenciam. Na relação dialética entre pensar e agir (FREIRE, 1981), a conscientização conduz à emersão como caraterística de libertação da consciência dos sujeitos. Os educandos produzem conhecimento crítico, pois, independentemente do grau de escolaridade, "ninguém é ignorante de tudo" (GADOTTI, 1997, p. 6). Por meio do processo de reflexão-crítica sobre a realidade social, os sujeitos reelaboram as experiências vivenciadas em diferentes contextos, formal, não formal e informal (FREIRE, 1981; LIMA; GUIMARÃES, 2018). Dessa forma, a experiência dos educandos é transformada em conhecimento útil para e na transformação social, na ação de partilha com outros sujeitos, a partir da dialogicidade.

Ora, a dialogicidade, como componente da educação como prática de liberdade, remete para o entendimento do pensamento e da palavra dos educandos como sujeitos ativos; visa simultaneamente à transformação da realidade social e à busca permanente da humanização da educação. Assim, "nasce de uma matriz crítica e gera criticidade" no processo educativo (FREIRE, 1967, p. 107) e promove a prática de liberdade a partir do momento em que leva os sujeitos a exporem os seus pensamentos sobre a realidade. Humaniza, igualmente, o conhecimento e socializa o processo educativo (FREIRE, 2018; GADOTTI; TORRES, 2009). Como ato de pronunciar conscientemente o mundo, a comunicação entre o educador e o educando é realizada de forma horizontal (FREIRE, 1967; GADOTTI, 1997). A relação entre esses dois atores educativos é mediada pelo conhecimento construído a partir da realidade e com a participação do educando, bem como pela experiência sistematizada do educador. A forma como se pensa o mundo, a maneira de agir diante dos problemas em busca de soluções, assim como a visão dos educandos sobre o que existe à sua volta, constituem caraterísticas fundamentais na manifestação da liberdade, como também integram o conteúdo programático trabalhado nos espaços onde são realizadas atividades de educação de adultos, como nos círculos de cultura (FREIRE, 1967). Nessa ordem de ideias, o educador não é visto como o 
detentor do conhecimento a priori, construído fora da realidade dos educandos, assim como os educandos não são tidos como elementos desprovidos de conhecimento e experiências. Ambos são educadores e educandos, sujeitos biófilos, no sentido em que são atores das suas ações fundamentadas num contexto histórico e social específico (GADOTTI, 1997; FINGER; ASÚN, 2003; FREIRE, 2018), empenhados na promoção de sociedades participativas, democráticas e emancipatórias (LIMA; GUIMARÃES, 2018).

\section{Lógicas políticas: uma proposta de análise}

Os conceitos de Freire aqui mencionados são importantes na discussão de Lima e Guimarães (2018), que propõem três lógicas de políticas de educação de adultos. Entre essas lógicas, as dimensões políticas e educativas subjacentes à lógica democrática e emancipatória estão mais próximas dos contributos do autor em análise. No que se refere às dimensões políticas, essas orientam-se para a construção de sociedades mais inclusivas, igualitárias e participativas, nas quais se conta com a ação do maior número de atores sociais. Quanto às prioridades educativas, a mudança social, econômica e cultural apresenta-se como uma finalidade essencial, sendo a educação considerada um processo de empoderamento, um mecanismo de emancipação, bem como um direito social básico. Complementarmente, valores como solidariedade, justiça social e bem coletivo são basilares à promoção de ações educativas.

Para lá da lógica democrática e emancipatória, outras duas podem ser encontradas: a lógica de modernização e controle estatal e a lógica de recursos humanos (LIMA; GUIMARÃES, 2018), que se afastam do pensamento de Freire (1967, 1981, 2018), nomeadamente no que tange à educação como prática de liberdade. No que diz respeito à lógica de modernização e de controle estatal, as dimensões políticas acentuam projetos e iniciativas de educação de base, designadamente de alfabetização funcional, adaptativa e de segunda oportunidade. Nessa lógica, o controle social exercido pelo Estado é destacado. O planejamento, traduzido em regras formais, muitas delas de caráter burocrático, é implementado tendo por base orientações mais características do Estado-providência, por exemplo. No caso das dimensões educativas, nessa lógica, a formação profissional, influenciada pelo formato escolar mais tradicional, propõe-se 
promover a adaptação do trabalhador ao posto de trabalho, mudanças econômicas e ao aumento da produtividade.

Quanto à lógica de recursos humanos (LIMA; GUIMARÃES, 2018), as dimensões políticas pautam-se pelo crescimento econômico, pelo aumento da produtividade, da competitividade e da empregabilidade dos adultos trabalhadores, já que a educação e a formação encontram-se a serviço do desenvolvimento do capital humano. No âmbito das dimensões educativas, a educação de adultos e, particularmente, a aprendizagem ao longo da vida assumem preocupações de adaptação social, econômica e educativa, sendo o cidadão considerado um consumidor detentor de liberdade de escolha e responsável pelas suas opções de educação e formação, por isso a educação de base e, sobretudo, a formação profissional obedecem aos imperativos do aumento das competências e da aquisição de competências com valor no mercado de trabalho. A educação, em todas as modalidades (formal, não formal e informal), ganha valor de mercado, uma vez que as aprendizagens efetuadas pelos adultos podem traduzir-se em investimentos com retorno econômico.

\section{Opções metodológicas tomadas}

O presente artigo procura responder à seguinte questão: que prioridades políticas e educativas enunciadas nas Recomendações de Educação e Aprendizagem de Adultos da UNESCO (UNESCO, 1977, 2017) remetem ao contributo de Paulo Freire, nomeadamente ao conceito de educação como prática de liberdade? Para a obtenção da resposta à tal pergunta recorreu-se à análise documental de Bowen (2009), que inclui três níveis de leitura dos documentos selecionados: uma leitura flutuante dos textos, que permitiu uma análise superficial do seu conteúdo; uma leitura cuidada, mais aprofundada dos textos, tendo em consideração a questão e as categorias de análise, como a presença/ausência dos conceitos de Freire $(1967,1981,2018)$ e das dimensões das lógicas políticas (LIMA; GUIMARÃES, 2018) presentes nos documentos em causa; e a interpretação do conteúdo dos documentos em análise (BOWEN, 2009), a partir dos conceitos de Freire $(1967,1981,2018)$ já abordados neste artigo e do trabalho de Lima e Guimarães (2018). Nesse processo, combinaram-se elementos da análise de contéudo e da análise temática. A análise de conteúdo assenta-se no processo de organizar a informação a partir de categorias que decorrem da questão de investigação, enquanto a 
análise temática procura padrões nos dados recolhidos, temas emergentes que se relacionam com as categorias estabelecidas e que permitem a discussão e a interpretação da informação em questão, num processo mais cuidadoso e rigoroso de codificação (BOWEN, 2009).

A partir das lógicas políticas de Lima e Guimarães (2018), com destaque para os conceitos de Freire de educação como prática de liberdade e problematizadora, conscientização e dialogicidade (FREIRE, 1967, 1981, 2018) - centrais na lógica democrática e emancipatória -, as duas recomendações da UNESCO são debatidas neste artigo.

\section{Desde a lógica democrática e emancipatória até a de recursos humanos: o esmorecimento do contributo de Freire nos documentos da UNESCO}

A UNESCO surge como uma importante organização governamental internacional, nomeadamente no processo de institucionalização global da educação de adultos como domínio de políticas públicas (FINGER; ASÚN, 2003; ELFERT, 2015). Essa organização orienta, coordena e supervisiona vários programas e projetos em todo o mundo, assim como difunde orientações sobre educação de adultos, sendo, neste caso, evidente a sua influência normativa (NEMETH, 2016). Nesse sentido, Milana (2016) considera essa a mais importante organização governamental internacional nesse campo e identifica três tipos de mobilização nos trabalhos desenvolvidos pela UNESCO. O primeiro tipo se refere ao landmarking enquanto "processo de construção conjunta de um passado comum” (MILANA, 2014, p. 52) na educação de adultos, evidenciado, por exemplo, na publicação dos relatórios Faure (FAURE et al., 1972) e Delors (DELORS et al., 1996) (MILANA, 2014, p. 52). O segundo tipo de mobilização diz respeito ao brokering, dado que a UNESCO também estabelece relações com os outros atores não governamentais, com o objetivo de prestar "apoio à transação de valores, ideias e informação entre agenciadores individuais e coletivos que envolvem a imaginação e a construção de um futuro sustentável para a educação de adultos" (id., ibid.). O terceiro tipo, o framing, consiste num "processo de estruturação da informação e das intenções políticas numa tentativa de produzir mudanças materiais em nível governamental" (id., ibid.), como os documentos em análise neste artigo. 
A UNESCO tem produzido um conjunto significativo de documentos políticos em diversos domínios, como no caso da educação de adultos,entre eles a Recomendação sobre o Desenvolvimento da Educação de Adultos (UNESCO, 1977), redigida durante a $19^{a}$ Conferência Geral da UNESCO, realizada em Nairobi (Quênia) em 1976. Nessa recomendação podem ser encontradas orientações sobre o desenvolvimento da educação de adultos que remetem mais claramente para a lógica política democrática e emancipatória (LIMA; GUIMARÃES, 2018). Esse documento enquadra-se no pensamento de Freire, visto que aproxima-se dos conceitos de educação como prática de liberdade e problematizadora, conscientização e dialogicidade (FREIRE, 1967, 1981, 2018).

Nessa recomendação define-se educação de adultos como conceito amplo que favorece o desenvolvimento político, social, econômico e cultural das sociedades, segundo a perspetiva da educação permanente (CANÁRIO, 2013). Quanto à dimensão política, o documento destaca a importância desse domínio na promoção de valores democráticos e do respeito entre os diferentes grupos sociais. Nesse sentido, as atividades de educação de adultos destacadas nas diferentes modalidades, formal, não formal e informal, contribuem para a conscientização do sujeito (FREIRE, 1967, 1981), pois permitem a compreensão crítica do mundo envolvente, bem como o “desenvolvimento integral da personalidade" e da sociedade (UNESCO, 1977, p. 169). Para esse efeito, as finalidades da educação de adultos se assentam nos princípios da disponibilidade, do interesse e das aspirações do educando, considerando as condições social, cultural e econômica do sujeito, da igualdade e justiça social, da democracia e emancipação e da experiência adquirida pelos adultos ao longo da sua vivência.

A recomendação de 1976 denota a importância atribuída à educação de adultos como uma área de políticas públicas consistente e alargada. Essa circunstância informa dois aspetos: um primeiro que orienta as políticas públicas de educação de adultos como parte integrante do quadro legislativo de cada Estado, sob a forma de Lei de Bases, por exemplo, ou outra legislação equivalente; e um segundo que diz respeito ao desenvolvimento das políticas públicas por meio de instituições administrativas públicas (como o Ministério da Educação e outros organismos estatais) e de entidades que localmente levam a cabo os programas estabelecidos, como escolas, entidades privadas ou organizações da sociedade civil. Assim, as organizações do terceiro setor, designadamente aquelas que se caracterizam pela democracia e autogovernação, 
ganham relevância. Esclarece-se que essas organizações podem participar do processo de definição, desenvolvimento, acompanhamento e avaliação das políticas públicas e dos respetivos programas, numa dinâmica de baixo para cima, abrindo espaço para o debate construtivo e o reforço de democracia participada. Várias atividades educativas, como a alfabetização, a formação profissional e a educação cívica, política e sindical, são enunciadas nessa recomendação (UNESCO, 1977; CANÁRIO, 2013; ELFERT, 2015). A variedade das atividades indicadas demonstra o entendimento da educação de adultos não como um fim em si mesmo, mas como um processo desenvolvido com os outros setores sociais que também contribuem para a autonomia do sujeito e da sociedade (LIMA; GUIMARÃES, 2018).

No que toca à dimensão educativa, podemos encontrar, na Recomendação sobre o Desenvolvimento da Educação de Adultos, de 1976, orientações que levam ao entendimento de educação de adultos heterogênea e diversificada (CANÁRIO, 2013) e de "natureza crítica e reflexiva" (GUIMARÃES, 2011, p. 228). Nessa recomendação, o conceito de educação de adultos emerge a partir de uma perspetiva heurística, visando ao "desenvolvimento integral do homem e de uma participação no desenvolvimento socioeconómico e cultural equilibrado e independente" (UNESCO, 1977, p. 168). Nesse sentido, a educação de adultos abrange diversos conhecimentos, desde habilidades básicas (escrita, leitura e cálculo) a outras mais complexas (de compreensão, análise crítica, cidadania ativa e produção de saberes diversos), bem como o aperfeiçoamento de qualificações profissionais que permitem aos adultos participar de forma ativa e reflexiva da transformação da realidade socioeconômica por meio do trabalho. Seguindo o pensamento de Freire, os educandos são vistos como os principais atores do processo educativo, no sentido em que atuam de forma efetiva para a transformação da realidade social, política, econômica e ambiental mediante suas ações combinadas de reflexão crítica e ação (FREIRE, 1967, 1981, 2018).

Essa recomendação considera que os métodos utilizados nas ações de educação de adultos devem ter em conta as motivações, as potencialidades e os obstáculos dos adultos em formação, a experiência adquirida pelos sujeitos ao longo das suas vivências socioprofissionais e familiar e a identificação dos reais problemas dos educandos. Essas ações também devem privilegiar a dialogicidade entre o educador, na qualidade de facilitador e motivador de novas aprendizagens, e o educando, como o ator principal da aquisição de saberes. Dessa forma, os métodos das atividades educativas rompem com 
as abordagens instrumentalizadas e transmissivas, típicas das iniciativas escolares, e favorecem a problematização e a conscientização (FREIRE, 1967, 1981, 2018) da realidade social em transformação. Com o objetivo de favorecer o alargamento de participação dos adultos no processo socioeducativo, considera-se importante recorrer a métodos pedagógicos, como grupos de estudo, apoio educativo aos membros da comunidade (professores, estudantes e voluntários), unidades móveis e participadas de ensino e programas de incentivo ao autodidatismo (UNESCO, 1977) que fomentam a dialogicidade. Esses métodos visam a desenvolver nos adultos valores como solidariedade, ajuda mútua, colaboração na realização dos trabalhos, bem como instigam a participação e a tentativa de desafiar a normalidade para a transformação da realidade (FREIRE, 1967, 1981, 2018).

A Recomendação sobre Aprendizagem e Educação de Adultos, de 2015, que toma o lugar da recomendação de 1976, foi elaborada no âmbito da $38^{\text {a }}$ Conferência Geral da UNESCO, realizada em Paris (França). Ao contrário do documento de 1976, parte do conceito de educação e aprendizagem de adultos enquanto binômio de componentes importantes para a realização do direito à educação. Essa definição destaca a finalidade de os adultos poderem atuar efetivamente na mudança da realidade política, econômica, social, cultural, ambiental e tecnológica por meio dos princípios de participação, acessibilidade, adaptabilidade e aceitabilidade, conforme a realidade de cada Estado. Nesse âmbito, registra-se um paralelo com a recomendação anterior, mas, em relação à dimensão política, esse documento se baseia na perspetiva da aprendizagem ao longo da vida, conceito desenvolvido à luz das caraterísticas contemporâneas da vida política, econômica, social, ambiental e cultural, evidenciadas, sobretudo, nas transformações socioprofissionais que ocorrem no mundo do trabalho, com a entrada de novas e complexas tecnologias. Objetiva, por isso, dar respostas aos desafios impostos pelo fenômeno da globalização. Assim, a recomendação articula-se com a Agenda 2030 da Organização das Nações Unidas, que tem nos Objetivos de Desenvolvimento Sustentável o seu mais significativo desígnio (UNESCO, 2017, p. 5).

No que à dimensão educativa diz respeito, a inclusão e a equidade são conceitos enfatizados nessa recomendação. Complementarmente, as atividades de aprendizagem e educação de adultos devem ser abordadas com base nas caraterísticas socioculturais de cada povo e comunidade. Esses conceitos poderiam sugerir a influência do contributo de Freire quanto à educação como prática de liberdade, mas as ações educativas a levar 
a cabo destinam-se especialmente a grupos específicos, designadamente os mais vulneráveis e marginalizados, "como pessoas com baixa ou nenhuma escolaridade, trabalhadores migrantes, trabalhadores desempregados, membros de minorias étnicas, grupos indígenas, indivíduos com deficiência, pessoas encarceradas, idosos, pessoas afetadas por conflitos ou desastres, refugiados, apátridas ou deslocados” (UNESCO, 2017, p. 11). Apesar da aparente abrangência da definição de educação (e aprendizagem) de adultos, essa recomendação centra-se mais claramente em objetivos de transmissão de conhecimento, tendo em vista a adaptabilidade dos sujeitos aos contextos de vida diversos, como os de trabalho, não sendo possível identificar conceitos que possam ser atribuídos claramente a Freire, como educação como prática de liberdade e problematizadora, conscientização e dialogicidade (FREIRE, 1967, 1981).

Ao contrário do documento anterior, a recomendação de 2015 aponta com maior clareza para valores e princípios da lógica de gestão de recursos (LIMA; GUIMARÃES, 2018). Essa recomendação se fundamenta na perspetiva da aprendizagem ao longo da vida e visa a dar respostas aos desafios impostos pelo fenômeno da globalização nas suas diferentes facetas. Nesse sentido, procura responder aos desafios impostos pelo setor produtivo devido à internacionalização da economia (UNESCO, 2017). Nesse documento, a aprendizagem e a educação de adultos (e não a educação de adultos apenas) são definidas como componentes fundamentais da aprendizagem ao longo da vida (e não educação permanente, conceito mais próximo das ideias de Freire). Dessa maneira, a prioridade da educação de adultos abrange todas as formas de educação e aprendizagem, formal, não formal e informal, que permitem a plena participação dos sujeitos na vida em sociedade, bem como a entrada e permanência no mundo do trabalho, procurando, assim, dotar os educandos de conhecimentos, competências, capacidades, habilidades e experiências úteis à vida profissional, para o desenvolvimento individual e das organizações de trabalho (LIMA; GUIMARÃES, 2018).

A recomendação de 2015 destaca articulações intersetoriais, tendo em vista integrar e envolver diversos atores (organizações da sociedade civil, universidades, empresas com fins lucrativos). O documento indica que as estruturas de governança das políticas públicas devem assegurar a representação e participação de atores interessados, de modo a promover a transparência e a democracia, mas tendo sempre como objetivo 
mais destacado dar resposta às necessidades do mercado de trabalho. Dessa forma a educação de adultos é instrumentalizada no desenvolvimento do capital humano, no sentido em que serve o setor econômico na preparação da mão de obra qualificada (LIMA; GUIMARÃES, 2018). Os sujeitos, na qualidade de formandos-trabalhadores, cumprem percursos formativos em função dos imperativos profissionais, bem como também são vistos como os principais financiadores da sua formação, o que pode sugerir a retração do Estado no que diz respeito à disponibilização e à generalização de ofertas educativas.

Relativamente à dimensão educativa, a educação e a aprendizagem de adultos se propõe a dotar os educandos de conhecimentos, competências, habilidades e experiências para atuarem, sobretudo, no mundo do trabalho, já que todas as aprendizagens adquiridas, nos diferentes espaços e tempos da vida, são válidas para o desenvolvimento econômico. Por isso a aprendizagem ao longo da vida é um meio que visa, especialmente, a fomentar a produtividade, a competitividade e o crescimento econômico (LIMA; GUIMARÃES, 2018). Assim, a recomendação de 2015 privilegia os métodos que remetem a uma abordagem vocacionalista e instrumentalizadora, que promovem a aprendizagem individualizada em detrimento de abordagens que reportam a educação como prática de liberdade e problematizadora, a conscientização e a dialogicidade (FREIRE, 1967, 1981, 2018).

\section{Notas conclusivas}

Por ocasião do centenário do nascimento de Paulo Freire, em 2021, diversas são as ocasiões nas quais se discute o contributo desse autor para a reflexão teórica e política. Entre essas ocasiões, consta o dossiê que compõe os trabalhos desta revista. No seguimento do trabalho de reflexão que temos desenvolvido no que se refere às lógicas políticas de educação de adultos (LIMA; GUIMARÃES, 2018), designadamente no papel realizado por organizações governamentais internacionais, como a UNESCO, este artigo surgiu como uma oportunidade de discutir as interseções entre o pensamento de Freire e a produção política normativa (MILANA, 2014; NEMETH, 2016) da referida entidade. A Recomendação para o Desenvolvimento da Educação de Adultos (1976) e a Recomendação sobre a Aprendizagem e Educação de Adultos (2015) emergiram, assim, como objetos de análise preferenciais pela importância que têm tido na reflexão 
acadêmica, nomeadamente pela utilização que inúmeros autores fazem da definição de educação de adultos/educação e aprendizagem de adultos e de educação permanente/aprendizagem ao longo da vida que nesses documentos podem ser encontradas e das possibilidades de transferência política para os diversos países que esses textos encerram, dada a importância atribuída por eles à concessão e ao desenvolvimento de políticas nacionais dos Estados que constituem a UNESCO. A discussão realizada neste artigo permitiu mostrar a relevância do conceito abrangente de educação de adultos e o destaque concedido à educação permanente no documento de 1976 (UNESCO, 1977), mais claramente em linha com os conceitos de educação como prática de liberdade e problematizadora, conscientização e dialogicidade de Freire (1967, 1981, 2018), e o esmorecimento e até a ausência em muitas partes da recomendação de 2015 do contributo de Freire (UNESCO, 2017), acompanhados da ênfase atribuída à lógica de recursos humanos (LIMA; GUIMARÃES, 2018) no texto em causa.

Essa circunstância leva-nos, por isso, a questionar essa mudança e sua influência nas orientações políticas e educativas da UNESCO e das políticas nacionais dos países que integram essa entidade. Em boa verdade, o contributo de Freire remete a um entendimento humanista e de pedagogia crítica da educação de adultos. Aposta na educação política dos educandos para a transformação social, cultural, econômica, ambiental e cívica. Permite antever o papel da educação (como prática de liberdade e problematizadora) na conscientização. Desvela a importância da dialogicidade nas ações educativas simétricas entre educadores e educandos, em termos de relações de poder, e promotoras de justiça social. Seguindo essa linha de pensamento, uma mudança na definição da educação de adultos para educação e aprendizagem de adultos, no quadro da aprendizagem ao longo da vida, e um maior centramento da política e das práticas de educação nos sujeitos e nas suas opções em termos de percursos de desenvolvimento pessoal e social, sugere riscos que não podem deixar de ser enunciados neste artigo. São, sobretudo, riscos associados à instrumentalização das políticas públicas aos imperativos do desenvolvimento econômico e à preferência por práticas de educação bancária que retiram aos educandos as oportunidades de pensamento crítico e de ação social transformadora. Por essa razão, este artigo inclui também uma chamada de atenção aos investigadores no campo das políticas educativas, aos atores políticos e aos 
educadores e educandos, relativa à importância de se continuar a pensar a educação de adultos como efetiva prática de liberdade.

\section{Referências}

BOWEN, G. A. Document analysis as a qualitative research method. Qualitative Research Journal, v. 9, n. 2, 2009. DOI 10.3316/QRJ0902027.

CANÁRIO, R. Educação de adultos - um campo e uma problemática. Lisboa: Educa, 2013.

DELORS, J. et al. Learning: the treasure within. Report to UNESCO of the International Commission on Education for the Twenty-First Century. Paris: UNESCO, 1996.

ELFERT, M. Learning to Live Together: Revisiting the humanism of the Delors Report. Paris: UNESCO Education Research and Foresight (ERF Working Papers Series, No. 12), 2015. Disponível em: http://unesdoc.unesco.org/images/0023/002338/233814e.pdf Acesso em: 20 jul. 2021.

FAURE, E., et al. Learning to Be. The world of education today and tomorrow. Paris: UNESCO/Harrap, 1972.

FINGER, M. \& ASÚN, J. M. A Educação de Adultos numa Encruzilhada: Aprender a nossa saída. Porto: Porto Editora, 2003.

FREIRE, A. M. Educação para a paz segundo Paulo Freire. Educação, ano XXIX, n. 2 (59), 2006.

FREIRE, P. Educação como prática da liberdade. Rio de Janeiro: Paz e Terra, 1967.

FREIRE, P. Ação cultural para a liberdade e outros escritos. Rio de Janeiro: Paz e Terra, 1981.

FREIRE, P. Pedagogia do oprimido. Porto: Edições Afrontamento, 2018.

GADOTTI, M. Lições de Freire. Revista da Faculdade de Educação, v. 23, n. 1-2, 1997.

GADOTTI, M. \& TORRES, A. Paulo Freire: Education for Development. Development and Change, v.40, n. 6, 2009.

GUIMARÃES, P. Políticas de Educação de Adultos em Portugal (1999-2006): a emergência da educação e formação para a competitividade. Braga: Universidade do Minho - Instituto de Educação, 2011.

LIMA, L. C. A pedagogia do oprimido como fonte para a crítica ao pedagogismo opressor. Educação, Sociedade \& Culturas, v. 54, 2019. 
LIMA, L. C. \& GUIMARÃES, P. Lógicas políticas da educação de adultos em Portugal. Cadernos de Pesquisa, v. 48, n. 168, 2018.

MAYO, P. Critical literacy and emancipatory politics: the work of Paulo Freire. International Journal Educational Development, v. 15, n. 4, 1995.

MILANA, M. Unesco, educação de jovens e adultos e mobilização política. Revista Temas em Educação, v. 23, n. 2, 2014.

MILANA, M. Global polity in adult education and UNESCO: landmarking, brokering and framing policy. Globalisation, Societies and Education, v. 14, p. 2, 2016. DOI: 10.1080/14767724.2015.1010437.

NEMETH, B. Critical overview of the roles of international organisations in the development of adult learning and education. In: SLOWEY, M. (Ed.), Comparative Adult Education and Learning. Firenze: Firenze University Press, 2016, p. 117-139.

UNESCO. CONFINTEA. Declaração de Hamburgo. Agenda para o Futuro. Brasília: SESI/UNESCO, 1999.

UNESCO. Recomendação sobre o Desenvolvimento da Educação de Adultos. Conferência Geral da UNESCO. Braga: Universidade do Minho/Unidade de Educação de Adultos, 1977.

UNESCO. Recomendação sobre Aprendizagem e Educação de Adultos. 2015. Brasil: UNESCO, 2017.

Recebido em 04/08/2021

Aprovado em 14/09/2021

Publicado em 29/10/2021 